Artigo recebido em:

25.02.2019

Aprovado em:

30.03.2019

Marcio Serelle

Professor do Programa de Pós-Graduação em

Comunicação Social da

PUC Minas, com pós-

-doutorado na University

of Queensland (2015).

E-mail: marcio.serelle@ gmail.com.

\section{Reconhecimento como}

categoria de crítica

cultural

Marcio Serelle

\section{Resumo}

Neste artigo objetivo investigar as articulações entre política do reconhecimento e crítica cultural. Examino como a crítica jornalística de ficção audiovisual manifesta aspectos desse paradigma por meio de três relações não excludentes: a identificação e análise do reconhecimento como perspectiva estruturante da obra; o reconhecimento como valor de aferição; e como demanda mais complexa por paridade imagética. Para isso, analiso a crítica de filmes como Pantera Negra e O estranho que nós amamos. Os resultados apontam para a emergência de uma crítica menos estética do que ética, que privilegia aspectos identitários das personagens e questões de representatividade na indústria audiovisual. $\mathrm{O}$ artigo propõe, ao final, o desafio de se articular o valor de reconhecimento a fatores estéticos para uma análise mais ampla do discurso audiovisual.

Palavras-chave: Reconhecimento. Crítica cultural. Ficção audiovisual.

\section{Recognition as a category of cultural criticism}

\begin{abstract}
In this article i investigate articulations between the politics of recognition and cultural criticism. I examine how journalistic critique of audiovisual fiction manifests aspects of this paradigm through three non-excluding relations: the identification and analysis of recognition as a structuring perspective of the work; recognition as value; and as a more complex demand for imagery parity. For that, I analyze the critique of films like Black Panther and Beguiled. The results point to the emergence of a critique less aesthetic than ethics, which highlights the identity aspects of the characters and questions of representativeness in audiovisual industry. The article proposes, in the end, the challenge of articulating the value of recognition to aesthetic elements for a broader analysis of audiovisual discourse.
\end{abstract}

Keywords: Recognition. Cultural criticism. Audiovisual fiction.
Estudos em Jornalismo e Mídia Vol. 16 No 1 Janeiro a Junho de 2019 ISSNe 1984-6924 
proposta deste artigo é investigar como o paradigma do reconhecimento medeia, hoje, a relação da crítica com narrativas audiovisuais de ficção. Esse paradigma tem adquirido cada vez mais centralidade na política cultural, sobrepondo-se às reivindicações por redistribuição no campo das lutas por justiça social (SAFATLE, 2017; FRASER, 2003; DUNKER,

2017). Fortemente articulada a questões de ordem simbólica, a política do reconhecimento incide sobre as narrativas midiáticas e suas representações, que, por sua vez, estão implicadas no modo como fortalecemos (ou não) estimas sociais no cotidiano. As personagens de ficção, ainda que pertencentes a mundos autônomos em relação ao nosso, abrem possibilidades para que os públicos experimentem identidades por meio delas. Como escreveu Niklas Luhmann (2005, p. 105) acerca da função social do entretenimento moderno "é evidentemente sedutor experimentar em si mesmo realidades virtuais - ao menos numa fantasia que se pode interromper a qualquer momento". Assim, essas personagens ajudam-nos a trabalhar nossa própria identidade e refletem e projetam, sobre a vida prática, valores e modelos de comportamento que articulam, de modo complexo e não linear, o representado e o vivido.

No âmbito da crítica jornalística, o reconhecimento tornou-se, mais que chave para leitura de algumas obras, valor para apreciação delas. Interessa-me examinar neste artigo como a crítica jornalística contemporânea - aquela que analisa, em jornais, revistas, sites e blogs, obras em circulação - assimila e manifesta aspectos dessa política. Três tipos possíveis de relação serão considerados aqui, de modo não excludente: (I) a política do reconhecimento tornada estrutura, portanto elemento interno da obra, que a crítica busca identificar; (II) o reconhecimento como valor de aferição, ou, como desenvolverei adiante, a ideia de um "valor de reconhecimento"; (III) o reconhecimento como demanda por paridade imagística na cultura midiática, considerada pela crítica, mas não de forma unilateral.

$\mathrm{O}$ argumento, convém explicitar, não é moralizante, mas busca compreender as relações contemporâneas que, em contexto de políticas do reconhecimento, emergem entre ficção e sociedade e as implicações disso na crítica que, como "um duplo necessário" da obra (TODOROV, 2015, p. 7) examina as narrativas em contexto de prevalência desse paradigma.

Este trabalho divide-se em quatro partes, sendo a primeira esta introdução. $\mathrm{Na}$ segunda, conceituo, ainda que brevemente, dadas as dimensões deste artigo, o paradigma do reconhecimento a partir de Axel Honneth (2009) e Nancy Fraser (2003) e ressalto como essas políticas centram-se em questões simbólicas, o que faz das ficções audiovisuais de grande circulação midiática, como as abordadas neste artigo, objetos privilegiados para o debate identitário. Na terceira, parto do filme Pantera Negra e suas reverberações para discutir como a política do reconhecimento forja a ficção e torna-se valor para crítica. Como parâmetro, o reconhecimento abarca questões de representação e representatividade, mas, em face do caráter autônomo da ficção, argumento, em consonância com Antonio Candido (2000), que devemos pensá-lo em articulação com outros elementos e valores da crítica cultural. Por fim, nas considerações finais, recupero os aspectos principais e as incompletudes de uma crítica contemporânea orientada pela política do reconhecimento.

\section{Reconhecimento, narrativas e novos contextos de recepção}

A noção do reconhecimento foi retomada neste século por, entre outros autores, Axel Honneth (2009), que, a partir de Hegel e Mead, define-a como via de autorrealização dos sujeitos, dependentes da estima construída socialmente por meio das relações intersubjetivas. Honneth (2009) identifica três padrões de reconhecimento recíproco, referentes à sociabilidade primária, de amor e amizade no núcleo familiar e de amigos; ao âmbito das relações jurídicas, no campo dos direitos; e à diferença, que se manifesta em qualidades específicas de um indivíduo ou de um grupo que são reconhecidas, na comunidade, como contribuintes para se atingir os objetivos 
${ }^{1}$ No original: "Examples include cultural domination (being subjected to patterns of interpretation and communication that are associated with another culture and are alien and/ or hostile to one's own); nonrecognition (being rendered invisible via the authori-

tative representational, communicative, and interpretative practices of one's own culture); and disrespect (being routinely maligned or disparaged in stereotypic public cultural representations and/ or in everyday life interactions)".

${ }^{2}$ No original: "[...] what remains cogent and unsurpassable in the socialist vision with what is defensible and compelling in the apparently 'postsocialist' vision of multiculturalism [...]".

${ }^{3}$ No original: "Local particularities become transplanted to new ground, and something new and hybrid results".

da sociedade. $\mathrm{O}$ indivíduo que tem o reconhecimento negado e que vive formas de desrespeito e ofensa sofre danos na identidade e na autorrealização, com perdas que podem remeter à falta de autoconfiança, autorrespeito e autoestima. Experiências de denegação, segundo Honneth (2009), motivam lutas coletivas por reconhecimento, em que experiências privadas de lesão são interpretadas como referentes a todo um grupo. Para isso, faz-se uso de semânticas coletivas subculturais, que organizam conceitos tanto para expressar como para combater as injustiças sofridas.

Mesmo sendo crítica da concepção que toma o reconhecimento como categoria moral abrangente, Nancy Fraser propõe uma descrição desse paradigma, referenciada na política, que pode contribuir para iluminar nossa questão acerca da crítica jornalística da ficção audiovisual. Para Fraser (2003), o alvo do paradigma do reconhecimento são as injustiças compreendidas como culturais, de modo heterogêneo.

Os exemplos incluem a dominação cultural (estar sujeito a padrões de interpretação e comunicação associados a outra cultura e que são estranhos e lou hostis aos seus); o não reconhecimento (ser tornado invisível através de práticas autoritárias de representação, comunicação e interpretação da sua própria cultura); e desrespeito (ser rotineiramente difamado ou menosprezado em representações culturais públicas e estereotipadas e/ou interações da vida cotidiana) ${ }^{1}$ (FRASER, 2003, p. 13, tradução nossa).

O paradigma do reconhecimento abrange a política identitária, mas não se confunde com ela, pois também contempla tendências desconstrutivistas que, como as questões queer ou as que criticam a noção de "raça", refutam perspectivas essencialistas.

Antes de avançarmos, convém assinalar que, embora Fraser (2003) reconheça as diferenças entre as políticas de reconhecimento e de redistribuição, ela se recusa a vê-las como excludentes. Para ela, a justiça social hoje requer tanto uma como outra, na articulação de uma abordagem que integre "o que permanece irrefutável e insuperável na visão socialista com o que é defensável e convincente na visão aparentemente pós-socialista do multiculturalismo [...]" (FRASER, 2003, p. 94, tradução nossa) ${ }^{2}$. Essa demanda é sensível, por exemplo, no desafio imposto pelo caráter bidimensional de categorias como de gênero e "raça", cujas desigualdades e desrespeitos devem tanto à estrutura econômica como a padrões culturais e simbólicos, sendo que os dois âmbitos - o da má distribuição e o da falta de reconhecimento - devem ser considerados como primários, e não tipos de injustiça que seriam efeito indireto de um sobre o outro.

Fraser (2003) atesta, no entanto, que vivemos, hoje, a mudança da redistribuição para o reconhecimento, o que coloca esse último paradigma no centro da constelação de uma nova política cultural. Com sua ênfase no simbólico, a política do reconhecimento exerce influxos tanto na criação como na prática da crítica midiática.

As refilmagens podem ser um campo privilegiado da cultura midiática para observação de traços da política do reconhecimento nas obras, uma vez que são narrativas que viajaram de um período a outro, e, quando reapresentadas, dialogam com o novo contexto de recepção. Esse contexto se faz ainda mais visível no cotejo entre as versões, distanciadas temporalmente. Movimentos narrativos como esses, ainda que dentro de uma mesma cultura, nunca se dão sem entraves. Edward Said (1983), quando trata da circulação, dos empréstimos e apropriações de ideias, afirma que essas passagens acontecem sob pressão dos contextos, que colocam condições de aceitação ou mesmo resistências. As ideias migrantes se transformam para se acomodar às novas circunstâncias. Para Linda Hutcheon (2006), as adaptações, como transformações de obras anteriores, também obedecem a essa lógica. "Particularidades locais são transplantadas para um novo solo, e algo novo e híbrido surge" (HUTCHEON, 2006, p. 150, tradução nossa) $)^{3}$.

De modo geral, o mesmo acontece com as diversas formas de refilmagem e reinicialização - os chamados reboots, quando uma série, em nova versão, retorna ao início e propõe outras reconfigurações para a narrativa. Entre as muitas transformações na versão de 2018 da Netflix para Perdidos no espaço [Lost in space], nota-se o protagonismo dos papéis femininos, não apenas na família Robinson, mas na pró- 
pria personagem ambígua do dr. Smith (Parker Posey), também feminina na nova narrativa. À diferença da série de 1965, a filha mais velha da família, uma jovem que possui avançados conhecimentos de medicina, é negra (Taylor Russell), fruto de um relacionamento de Maureen Robinson (Molly Parker) antes de se casar com John Robinson (Toby Sthepens). Insere-se, ainda, uma personagem latina, Don West (Ignacio Serricchio, nascido na Argentina), ainda que em papel bastante sedimentado na gramática hollywoodiana, o de contrabandista. Convém argumentar, por fim, que a referência à personagem de Defoe, Robinson Crusoe, na série de 1965, já trazia acomodações, como a transformação do indivíduo náufrago em uma família, mais ajustada ao lar e ao ambiente doméstico da recepção televisiva.

O caso da refilmagem de $O$ estranho que nós amamos [The beguiled] (2017), por Sofia Coppola, é mais complexo, mas, ainda assim, tensionado por questões de reconhecimento. O filme é adaptado do romance de Thomas Cullinan e se passa na Guerra Civil estadunidense, no século 19. Na narrativa, um cabo ianque ferido (Colin Farrell) é acolhido por mulheres sulistas, de diversas idades, que convivem em um internato. Iniciam-se, assim, jogos de desejo e relações de opressão e sedução entre as personagens. No cotejo com o filme de 1971, dirigido por Donald Siegel, um crítico do The Guardian considerou a versão de Coppola ainda mais centrada no núcleo feminino ${ }^{4}$; outro ${ }^{5}$ assinalou que o apagamento da personagem negra e escrava foi uma estratégia para que o público contemporâneo tivesse mais empatia com as protagonistas - que não apareceriam como mulheres brancas opressoras de uma escrava. O crítico brasileiro Marcelo Hessel (2018, online) avaliou que: "A principal mudança que Coppola faz em seu roteiro é suavizar a história passada da personagem de [Nicole] Kidman, [que administra o internato]: de senhora incestuosa de fazenda, canalizadora de compulsões, ela se torna uma viúva moralmente defensável". Todos esses recursos narrativos ativaram mais intensamente os efeitos de sororidade para o ato final em que as mulheres decidem assassinar o soldado ianque.

Sobre a exclusão do papel da escrava, Coppola disse que essa foi uma decisão difícil, justificando-a com o argumento de que não desejava ter, naquele filme, uma personagem estereotipada, uma vez que não se sentia competente para desenvolvê-la coerentemente com a narrativa. A despeito da explicação, Coppola foi acusada de whitewashing, prática em que a indústria cinematográfica apaga identidades. $\mathrm{O}$ excerto abaixo é de um crítico do jornal britânico The telepraph:

Você pode argumentar: por que ela deveria ser forçada a descrever experiências de pessoas negras se ela acha que não pode fazer justiça a elas? Mas isso não é desculpa quando você vai especificamente atrás de material que possui um elemento racial. Das muitas histórias que ela podia ter contado sobre o amadurecimento feminino, por que escolher um cenário durante a Guerra Civil estadunidense, baseado em um livro em que uma personagem escrava possui destaque, se não se está interessado em aspectos raciais? Ela poderia facilmente ter escrito essa história em um contexto moderno, em uma escola secundária ou escolhido um período histórico, como Maria Antonieta, em que raça não é subtexto (AFTAB, 2017, tradução nossa) ${ }^{6}$.

Esses exemplos demonstram influxos da política do reconhecimento nas narrativas audiovisuais e na circulação delas. No caso do filme de Coppola, especificamente, há a questão apontada em que a positividade de determinada representação complexa e mais densa das mulheres resultou em outra disparidade, referente ao apagamento da identidade negra. A ficção torna-se objeto de interpretações e julgamentos acerca de formas possíveis de representação e reconhecimento e suas colateralidades.

Para não criarmos a falsa impressão de que a crítica centrada no reconhecimento é exclusiva de nosso tempo, podemos recuperar obras, como as de Richard Dyer (1998), dos estudos culturais de cinema, que apreenderam, na segunda metade do século 20, as personagens de ficção como representações que encarnam valores sociais e reproduzem normas de comportamentos. As personagens são elementos centrais na discussão sobre reconhecimento. E, pelo menos, desde a obra de Walter Lippmann (2008), Opinião pública, de 1922, em que a noção de estereótipo é sistema-
${ }^{4}$ Ver o texto de Peter Bradshaw em: https://www. theguardian.com/film/2017/ jul/13/the-beguiled-reviewsofia-coppola-nicole-kidman-colin-farrell-kirstendunst. Acesso em: 14 set.2018.

${ }^{5}$ Disponível em: $w w w$. telegraph.co.uk/ films/2017/07/14/sofia-coppola-has-race-problem-noexcuse/. Acesso em: 14 set. 2018.

${ }^{6}$ No original: "You might argue: why should she be forced to depict the experiences of people of colour if she feels she can't do them justice? But that's no excuse, when you have specifically sought out material with a racial element. Of all the stories she might have told about female coming-of-age, why choose one set during the American Civil War, based on a book where a slave character is prevalent, if you're not interested in race? She could just have easily wrote that story in a modern context, at a high school or chosen a historical period, such as with Marie Antoinette where race is not a subtext". 
tizada, discute-se se, de que modo e em que grau modelos adquiridos através da ficção midiática plasmam valores de nossa sociedade e tendem a informar nossa realidade.

\section{O valor de reconhecimento nas críticas a Pantera Negra}

${ }^{7}$ No original: "[...] the Wolf, the Devil, the Evil Spirit, the Bad Man, the Savage are always symbolized by Negroes or Indians."
Em crítica publicada na The new republic a Pantera Negra (2018), adaptação cinematográfica de quadrinhos Marvel, dirigida por Ryan Coogler, Jonathan W. Gray inicia o texto com referência a Franz Fanon, que, em 1952, escreveu que, nos quadrinhos, "o lobo, o diabo, o espírito maligno, o homem mau, o selvagem são sempre simbolizados por negros ou indígenas" (FANON apud GRAY, 2018, online). Essa passagem encontra-se na obra Pele negra, máscaras brancas, em que o filósofo propõe que há uma "constelação de dados" (FANON, 2008, p.135) na cultura midiática hegemônica do homem branco que, gradualmente, penetram no indivíduo negro, minando a autoestima dele. O argumento de Fanon (2008), a partir do estudo da sociedade antilhana, é o de que o jovem negro exposto a essas representações acaba por se identificar com o explorador branco, visto como o civilizador "que traz a verdade aos selvagens, uma verdade toda branca" (FANON, 2008, p. 132). Para esse jovem, o preto vive somente na África e é caracterizado na figura do senegalês. Muitas vezes, de acordo com Fanon, o antilhano só perceberá sua cor quando é confrontado, na Europa, com o branco colonizador, que se refere a ele do mesmo modo a que ao senegalês.

Para o crítico da The new republic, contudo, Pantera negra, o primeiro filme Marvel a ter como protagonista um homem não branco, opera em "um mundo à parte", se comparado às representações hegemônicas. Entre os méritos do filme, cita o fato de a obra se engajar em teorias pan-africanistas e aludir, por meio das personagens femininas fortes, a uma nova geração de ativistas africanas. O crítico conclui que Fanon ficaria orgulhoso com esse filme.

No texto de Gray (2018), entrelaçam-se estudo de psicologia cultural, produzido em campo acadêmico mais restrito, e crítica de cinema em revista, de difusão mais ampla. Essa circularidade sinaliza que aspectos antes atinentes a um âmbito de iniciados ganham visibilidade e passam ser divulgadas não somente na crítica cultural da imprensa, mas, como podemos facilmente identificar, em conversações de redes sociais sobre as narrativas midiáticas e as questões de reconhecimento. Ativa-se, assim, um importante complexo crítico, que coloca em diálogo diversas séries discursivas, mais ou menos institucionalmente autorizadas e que popularizam noções da semântica coletiva (HONNETH, 2009) dos movimentos identitários.

Pantera Negra é um exemplo produtivo para esta discussão porque nele é sensível o modo como a política do reconhecimento serviu à lógica da ficção. De imediato, pode-se afirmar que o reconhecimento fez com que esse filme massivo de super-heróis fosse debatido para além do circuito que geralmente se detém sobre esse tipo de narrativa. Como assinala Žižek, Pantera Negra foi saudado em um espectro político amplo, sendo que, mais à esquerda, o filme foi recebido como "afirmação hollywoodiana de representatividade e empoderamento negro" (ŽIŽEK, 2018, online).

A leitura mais imediata do filme, segundo Žižek (2018, online), leva ao desapontamento, uma vez que o projeto político, conduzido pelo herói T'Challa, é de um "globalismo gradual e pacífico, que operaria no interior das coordenadas da ordem mundial existente e suas instituições, disseminando educação e auxílio tecnológico, e ao mesmo tempo preservando a cultura e o modo de vida singulares de Wakanda”. Nesse sentido, Žižek (2018, online) não compreende como Fanon, "teórico da libertação negra [...] através da libertação violenta”, poderia se entusiasmar com esse filme. No entanto, para Žižek, uma segunda leitura é possível, pois o antagonista Erik Killmonger, à exemplo da personagem Bane, de Batman: o cavaleiro das trevas ressurge, não é um vilão convencional, pois nele há a marca do herói, expressa fortemente em sua cena final, de fala com forte impacto ético: "Jogue-me no oceano com meus antepassados que pularam dos navios, porque sabiam que a morte 
era melhor do que a escravidão" (ŽIŽEK, 2018, online). Para Žižek (2018, online), o momento que se segue, com os dois personagens panteras negras, de visões políticas diferentes, "compartilhando seus últimos momentos juntos após o desfecho da batalha - uma cena inimaginável em um filme tradicional de ação que geralmente culmina na virulenta destruição do inimigo [...]" é um convite à reflexão mais aprofundada acerca dessa ficção.

A crítica brasileira a Pantera negra foi também atravessada pelo reconhecimento. André Miranda (2018), de O Globo, identifica como elemento de novidade do filme - que, segundo ele, pode levar a uma possível e importante quebra de paradigma - a inserção "de um blockbuster de fantasia tão forte em problemas tão reais". $\mathrm{Na}$ conclusão do crítico, não são os elementos sociais que se inserem no filme, mas algo mais programático, em que a narrativa de ficção ingressa nos problemas reais do reconhecimento.

Ainda na relação entre ficção e sociedade, Miranda coteja o que compreende como as propostas do Partido dos Panteras Negras e a personagem dos quadrinhos, ambos criados em 1966. "Os Panteras Negras pregavam a luta direta pela liberdade social, enquanto que o Pantera Negra sugeria uma nova representação literária para jovens negros que não tinham o direito de se ver como protagonistas" (MIRANDA, 2018, online). Para Miranda, o filme articula bem essas ideias. O crítico avalia, ainda, que um dos "acertos" do filme está na representação das mulheres: "Elas são guerreiras, cientistas, rainhas, personagens bem mais interessantes do que a média em Hollywood. Entra as atrizes, Lupita Nyong'o, Danai Gurira, Letitia Wright e Angela Basset, todas negras, têm maior destaque" (MIRANDA, 2018, online).

Thales de Menezes (2018), da Folha de S. Paulo, inicia sua crítica pela análise de enredo, apontando, na trama, ecos shakespearianos. Por fim, coloca também em relevo as personagens "fortes" e o fato de o filme "caprichar" no elenco predominantemente negro. Menezes (2018, online) afirma que o filme, "o primeiro [...] blockbuster de super-herói protagonizado por afro-americanos e dirigido por um, Ryan Coogler" possui relevância evidente para a comunidade negra hollywoodiana. Além disso, "o filme também agrada às mulheres em sua luta interminável por trabalhos mais impactantes no cinema" (MENEZES, 2018, online).

Como se vê nesses breves exemplos, um dos pontos de valorização do filme está na projeção de personagens consideradas "fortes" ou "bem mais interessantes" - algo também apontado na crítica estadunidense de Gray - do que os papéis comumente destinados a indivíduos desses grupos identitários em Hollywood. Articula-se, assim, como valor, a questão de representação, no plano ficcional, e de representatividade, no que se refere à demanda por paridade participativa na indústria do cinema. Evidentemente, se este é um valor positivo no julgamento de Pantera Negra, ele pode ter valência contrária na avaliação de outros filmes, que a crítica entenda que falharam em reconhecimento. Podemos chamar a essa categoria de "valor de reconhecimento". Pantera negra possui, para essa crítica, valor de reconhecimento.

Podemos considerar que o reconhecimento tem se tornado, em certa medida, elemento interno das narrativas midiáticas, pois é componente de construção da obra, atuando sobre a constituição de personagens, ações e espaços ficcionais. Nesse sentido, deve ser função da crítica abordar esses aspectos. Mas de que modo, em que articulação a outros aspectos e em qual peso? Essas não são questões fáceis, uma vez que, como observa Fraser (2003), as próprias reclamações por reconhecimento implicam interpretação e julgamento, e podem ser campos controversos, que demandam uma abordagem dialógica, que implique as partes envolvidas, como no caso por ela citado da polêmica francesa acerca do foulard - mais especificamente, sobre a permissão do uso do véu islâmico por estudantes em escolas públicas. Fraser apresenta duas visões neste tipo de debate: na primeira, chamada por ela de populista, seus proponentes defendem que os próprios sujeitos de autoestima lesada são aqueles que devem ter a palavra final sobre as questões de reconhecimento atinentes a seu grupo; na segunda vertente, denominada por Fraser de "autoritária", conside- 
${ }^{8}$ No original: "No given view - neither that of the claimants nor that of the 'experts' - is indefeasible". ra-se que os teóricos dos reconhecimentos, os filósofos especialistas, devem decidir acerca das representações, com ponderações sobre o necessário para a formação da comunidade ética e humanista. Em contraste com essas abordagens, a via dialógica proposta por Fraser (2003) toma o reconhecimento como objeto de deliberação social. "Nenhuma das perspectivas - nem a dos reivindicantes nem a dos 'experts' - é irrevogável"8 (FRASER, 2003, p. 43, tradução nossa).

Nesse sentido, a crítica audiovisual pode assumir determinado papel nessa deliberação acerca do reconhecimento, uma vez que, em casos como os apresentados neste artigo, ela identifica e coloca em debate aspectos relacionados à representação de grupos subalternizados na indústria cultural. No entanto, nessa abordagem críti$\mathrm{ca}$, que valoriza de modo central o reconhecimento, permanece tanto o problema da vinculação direta entre a representação ficcional e o vivido como a questão referente a outros elementos e valores que devem ser observados na crítica.

Em ensaio da década de 1960, que pode contribuir para iluminar nossas questões, Antonio Candido (2000) expõe bem aquilo que identificou como núcleo do problema para a crítica quando esta trata das relações entre ficção e sociedade. Segundo Candido (2000), é preciso refletir sobre até que ponto fatores sociais tornam-se verdadeiramente elementos internos na condição de agentes da estrutura, articulados à estética da obra. Estes merecem o aprofundamento da crítica, pois, por meio da análise deles, alcança-se a relação entre aspecto e significado da obra. No nosso caso, haveria, portanto, a diferença entre a simples identificação e avaliação dos elementos ficcionais cortados ao paradigma do reconhecimento e a análise deles quando incorporados estilisticamente à fatura da obra.

Candido apoia-se em uma premissa moderna, que convém recuperarmos:

O primeiro passo (que apesar de óbvio deve ser assinalado) é ter consciência da relação arbitrária e deformante que o trabalho artístico estabelece com a realidade, mesmo quando pretende observá-la e transpô-la rigorosamente, pois a mimese é sempre uma forma de poiese (CANDIDO, 2000, p. 12).

Isso não quer dizer que uma obra de ficção, mesmo sendo discurso assumidamente encenado, esteja livre de estereótipos e preconceitos - e estes, quando existentes, devem ser apontados. Mas é preciso compreender a ficção, a partir de Wolfgang Iser (2002), como mediação entre elementos selecionados da nossa realidade e do imaginário, e isso significa também ter a noção de que nosso mundo emerge nela de forma transgredida, por mais documental que a narrativa pretenda ser.

Para Candido, deve-se buscar a interpretação dialeticamente íntegra. No contexto em que escreve, Candido (2000, p. 11) identifica muitas modalidades de estudo legítimas e fecundas em que "se nota o deslocamento de interesse da obra para elementos sociais que formam sua matéria, para as circunstâncias do meio que influíram na sua elaboração ou para a sua função social". No entanto, se esses são aspectos capitais para, por exemplo, o historiador e o sociólogo, eles não devem compor a totalidade da crítica. Esta deve ser fusional, no encontro entre o sociológico e estilístico, examinando como elementos da ordem social surgem na concepção estética, são filtrados por ela e trazidos no nível da criação. Isso permitiria compreender a singularidade e a autonomia das obras, sem abrir mão da historicidade dela e do pensamento coevo que a compõe.

Convém notar que Candido, como crítico moderno, opera no que Susan Sontag (1966) identificou como "projeto da interpretação", em que a análise dos elementos formais de uma obra permite escavar e acessar o texto. Os aspectos estéticos são relevantes como meio para se apreender tanto a singularidade da obra como as relações dela com o contexto. No caso especificamente da crítica exercida por Candido, valorizam-se bastante os elementos estéticos, como modo de organização artística que afeta o receptor e só assim faz atuar, nele, o conteúdo. A crítica baseada em questões do reconhecimento, contudo, parece adotar parâmetros mais éticos do que estéticos, 
com valorização inclusive de aspectos relacionados a condições de produção da obra.

Não há dúvida de que o reconhecimento desempenha um papel importante no jogo de fatores que motivam as narrativas midiáticas em geral. Porém, nessa concepção de crítica defendida por Candido, ele não seria tomado unilateralmente, mas, conjugado aos demais aspectos constitutivos de uma ficção. Um cinema brasileiro recente, o de Café com canela (2017), dirigido por Glenda Nicácio e Ary Rosa, e Arábia (2017), dirigido por João Dumans e Afonso Uchoa, desafia a crítica nesse ponto. Nele, o reconhecimento aparece amalgamado à fabulação. A visibilidade dada aos subalternizados, àqueles de raro protagonismo na produção audiovisual dominante, não se faz de modo a conformar uma luta identitária explicitada, ainda que, por outros meios, ela possa ser percebida. Trata-se mais do reconhecimento ao direito que esses sujeitos têm à representação ficcional de seus cotidianos. Em Café com canela, narra-se, entre outras histórias e em diversas linhas temporais, a vida de uma professora que, após a morte do filho, recolhe-se em casa. Paralelamente, a vida da comunidade majoritariamente negra, suas relações interpessoais, seus afetos, sua religiosidade articula-se de forma solidária. Arábia adota também outra via: a de um trabalhador que narra sua épica em uma estrutura fílmica em abismo. O reconhecimento aqui se torna uma reivindicação por autonomia e paridade imagística e por outras formas de representação que a crítica dificilmente pode abordar sem refletir sobre o que Candido chamava de "economia interna da obra", que é sua escritura, mas também modo político de inscrição no mundo.

\section{Considerações finais}

Em face da centralidade que a política do reconhecimento adquiriu hoje nas lutas por justiças sociais, é procedente que esse paradigma, fortemente estruturado no simbólico e atrelado às representações em circulação na cultura midiática, atue sobre a produção audiovisual e a crítica. Como busquei demonstrar, o paradigma do reconhecimento tem-se tornado elemento estruturante de narrativas fílmicas, notadamente no plano das ações e das personagens. O reconhecimento é, por exemplo, aspecto de atualização de narrativas, quando estas são refilmadas e devem dialogar com novos contextos de recepção, exigentes acerca da representatividade de movimentos identitários e atentos às representações.

O filme Pantera Negra, cuja recepção crítica foi brevemente abordada neste artigo, apresenta-se como produto audiovisual dentro da chave do reconhecimento. No caso, afirma-se um super-herói negro em um universo de blockbusters em que esse tipo de personagem é secundário. A afirmação de uma personagem negra na cultura midiática, dada a circulação dessas narrativas em nosso cotidiano, é um ato que contribui para o fortalecimento da autoestima de um grupo identitário e passa a ser visto como estratégia na luta por reconhecimento, que é valorizada pela crítica.

Pantera Negra coloca-nos dois pontos para reflexão acerca da crítica audiovisual contemporânea: primeiro, ele nos permite identificar a emergência de um valor de reconhecimento, uma vez que o filme foi apreciado para além do circuito que usualmente avalia esse gênero de entretenimento; segundo, o reconhecimento orientou a abordagem dos textos, que, em geral, destacaram a configuração das personagens, principalmente os papéis femininos, e estabeleceram relações entre texto e contexto a partir de questões atinentes ao movimento negro. $\mathrm{O}$ trabalho da crítica foi menos hermenêutico e menos de análise fílmica do que de identificação e valorização das questões políticas e sociais suscitadas pela obra. Em geral, a crítica que possui o reconhecimento como categoria de valor volta-se também para a estrutura de produção e seus profissionais, avaliando-os em termos de paridade e representatividade no processo coletivo de realização da narrativa audiovisual.

Um aspecto que não está no escopo desse artigo, mas que pode ser examinado em outro estudoé o modo como essevalor de reconhecimento tem atuado de forma revisionista, colocando novas questões à produção audiovisual do passado e revendo determi- 
nadas filmografias com base na ética da própria narrativa e dos realizadores. Isso recoloca, na crítica cultural, as relações entre os sujeitos criadores e suas obras, que a visada estruturalista havia apagado ou mesmo condenado na segunda metade do século 20.

Apontei, por fim, outra série de filmes em que a questão do reconhecimento está na reivindicação por tornar visíveis cotidianos até então invisibilizados na produção audiovisual hegemônica. Essas narrativas geralmente possuem público restrito, mas não se pode excluir a contribuição delas na proposição de novas formas audiovisuais, inclusive de audiência mais alargada, pois é preciso considerar o fator de reverberação que filmes como Arábia podem ter entre realizadores e crítica especializada. No entanto, o mais importante parece ser como a crítica do reconhecimento de ênfase social não consegue esgotar esses filmes, dada a complexidade narrativa e a elaboração estética deles. O desafio é, portanto, pensar como o valor de reconhecimento - sem dúvida, um critério de julgamento já instaurado em nossa época -, pode ser aliado a outros elementos de análise audiovisual na reconstituição do discurso fílmico de forma mais ampla.

\section{Referências}

AFTAB, Kaleem. Sofia Coppola has a race problem - and there's no excuse for it. Disponível em www.telegraph.co.uk/films/2017/07/14/sofia-coppola-has-race-problem-no-excuse. Acesso em: 14 set. 2018.

CANDIDO, A. Crítica e sociologia. In: CANDIDO, A. Literatura e sociedade. São Paulo: T. A. Queiroz, 2000. p. 3-15.

DUNKER, C. Subjetividade em tempos de pós-verdade. In: DUNKER, C. [et. all.]. Ética e pós-verdade. Porto Alegre: Dublinense, 2017. p. 11-41.

DYER, R. Stars. British Film Institute, 1998.

FANON, F. Pele negra, máscaras brancas. Salvador: EDUFBA, 2008.

FRASER, N. Social justice in age of identity politics: redistribution, recognition, and participation. In: FRASER, N., HONNETH, A. Redistribution or recognition? - a political-philosophical exchange. Londres; Nova Iorque, Verso: 2003. p. 7-109.

GRAY, J. W. The libertating visions of Black Panther. Disponível em: https:/newrepublic.com/article/147045/liberating-visions-black-panther. Acesso em: $27 \mathrm{dez}$. 2018.

HESSEL, M. O estranho que nós amamos - crítica. Disponível em: https://www. omelete.com.br/filmes/criticas/o-estranho-que-nos-amamos-critica. Acesso em: 09 nov. 2018.

HONNETH, A. Luta por reconhecimento. São Paulo: Editora 34, 2009.

HUTCHEON, L. A theory of adaptation. Londres: Routledge, 2006.

ISER, W. Os atos de fingir ou o que é fictício no texto ficcional. In: LIMA, L. C. Teoria da literatura em suas fontes, vol 2. Rio de Janeiro: Civilização Brasileira, 2002. p. 955-987. 
LIPPMANN, W. Opinião pública. Petrópolis, RJ: Vozes, 2008.

LUHMANN, N. A realidade dos meios de comunicação. São Paulo: Paulus, 2005.

MENEZES, T. Pantera negra agradará quem vê pouco densidade nos filmes da Marvel.

Disponível em: https://www1.folha.uol.com.br/ilustrada/2018/02/pantera-negraagradara-quem-ve-pouca-densidade-nos-filmes-da-marvel.shtml. Acesso em 27 dez. 2018.

MIRANDA, A. Pantera Negra. Disponível em: https:/oglobo.globo.com/rioshow/ critica-pantera-negra-22389223. Acesso em 27 dez. 2018.

SAID, E. W. Travelling theory. In: SAID, E. W. The world, the text, and the critic. Cambridge: Harvard University Press, 1983. p. 226-247.

SAFATLE, V. Por um conceito “antipredicactivo" de reconhecimento. Lua Nova. São Paulo, no. 94, p. 79-116, 2015.

SAFATLE, V. Só mais um esforço. São Paulo: Três Estrelas, 2017.

SONTAG, S. Against interpretation. New York : Farrar, Straus \& Giroux, 1966.

TODOROV, T. A crítica da crítica. São Paulo: Unesp, 2015.

ŽIŽEK, S. Dois panteras negras. Disponível em: https://blogdaboitempo.com. br/2018/02/27/zizek-dois-panteras-negras. Acesso em: 27 dez. 2018.

\section{Narrativas audiovisuais}

ARÁBIA. Direção: Affonso Uchoa, João Dumans. Brasil: Katásia filmes, 2017 (97min.).

CAFÉ com canela. Direção: Glenda Nicácio, Ary Rosa. Brasil: Rosza filmes produções, 2017 (102 min.).

O ESTRANHO que nós amamos. Direção: Don Siegel. Estados Unidos: The Malpaso Company, 1971 (105 min.).

O ESTRANHO que nós amamos. Direção: Sofia Coppola. Estados Unidos: American Zoetrope; FR Productions, 2017. (93 min.).

PANTERA negra. Direção: Ryan Coogler. Estados Unidos: Marvel Studios, 2018 (134min.).

PERDIDOS no espaço. Vários diretores. Estados Unidos: 20th Century Fox, 19651968 (3 temporadas, 84 episódios).

PERDIDOS no espaço. Vários direitores. Estados Unidos: Legendary Television, 2018 (10 episódios). 